\title{
El discurso panorámico del Museo de Arte Contemporáneo de la Universidad de Chile [MAC] y la historiografía del arte chileno
}

\section{The panoramic Discourse of the Museum of Con- temporary Art at the University of Chile [MAC] and the Historiography of Chilean Art}

\section{Pierre Chateau Cantillana}

Facultad de Artes, Universidad de Chile. Santiago, Chile.

pchateau@gmail.com

\section{Resumen}

Bajo el supuesto de que es necesario un análisis discursivo sobre el museo y la historia del arte como condiciones de posibilidad del discurso del arte contemporáneo, este análisis de caso plantea que el supuesto teórico del discurso del MAC entre 1946 y 1947 fue concebir, seleccionar y exponer la pintura chilena como un panorama representativo tanto de la actividad artística como de la nación misma. Esta idea además implica una arraigada creencia sobre el desarrollo del arte chileno: la evolución formal del arte chileno es paralela a la formación de la nación; desde los orígenes de la República a principios del siglo xIx hasta los años cuarenta del siglo xx, el arte se concibe como un espejo de la nación en sus costumbres y paisajes.

Palabras clave: MAC, museografía, panorama, patrimonio nacional, pintura chilena.

\section{Abstract}

From the premise that a discourse analysis about the Museum and the History of Art as conditions of possibility of Contemporary Art discourse is required, this event analysis suggests that the subject of theoretical discourse of the MAC between 1946 and 1947 is to conceive, to select and to display the Chilean painting as a representative overview of the artistic activity and of the nation itself. This also supposes a deeply rooted belief about Chilean art development: the formal evolution of art runs parallel to the emergence of the nation from the beginning of the Republic until the forties of twentieth century, the first one is conceived as a mirror of the second one in its landscapes and genre paintings.

Keywords: MAC, Museography, Overview, National Patrimony, Chilean Painting. 


\section{Presentación}

Tal como se plantea en la introducción del libro La Construcción de lo Contemporáneo. La Institución Moderna del Arte en Chile (1910-1947), la historia del arte hecha en Chile gira en torno a una premisa única de perspectiva metodológica, que más allá de las diferencias que puedan encontrarse en la escritura sobre el arte chileno, está siempre presente como una constante que pasa casi inadvertida, pero que no por ello es menos importante. El concepto que acuñan Berríos, Cancino y Santibáñez para designar este paradigma de escritura en la historiografía del arte chileno -aunque no solo chileno- es el de "obracentrismo" (15). Aquí se reúnen esas dos escuelas que distinguen los autores en torno a la situación de las artes en Chile: una, que podríamos considerar como seguidora del formalismo de Heinrich Wölfflin, está centrada en la categorización de las obras de arte según sus elementos compositivos internos. La otra, influida por la Historia Social del Arte de Arnold Hauser y la Sociología del Arte de Pierre Francastel, otorga más importancia al contexto para comprender las artes dentro de un espacio y tiempo determinado, con el acento puesto en el mercado, las clases sociales que acceden a estas prácticas y, sobre todo, las condiciones de producción material y simbólica de aquellas. Sin embargo, ninguna de estas escuelas cuestiona lo que entiende por arte al momento de escribir sobre él, y tan solo cambia el punto de partida de dicha historia. Este consenso sobre lo que se entiende por arte, más allá de dónde esté puesto el énfasis al tiempo de estudiarlo, supone además un acuerdo sobre dónde radica, para cada sociedad, el concepto de arte. Al ubicarlo siempre en la obra, se genera una automática escritura que gira en torno a su contexto de producción y a los significados que pueda encarnar; estos, a su vez, pueden descubrirse investigando y refiriendo a la vida del artista, su biografía y sus influencias al momento de trabajar.

Por el contrario, aquí consideramos las imágenes en su más amplia expresión, no solo como arte sobre el cual se produce una contemplación estética desinteresada de raíz kantiana, sino como un vehículo transmisor de mitos, ideas y valores. En este sentido, este trabajo no se centra en las obras ni en los artistas para explicar una parte de la historia del arte chileno. En efecto, el objeto de estudio de la investigación es la institución del Museo de Arte Contemporáneo [MAC], dependiente de la Facultad de Artes de la Universidad de Chile ${ }^{1}$, durante el año de su fundación. Si se mencionan obras de arte (particularmente pinturas), es solo para ayudar a una mejor comprensión de nuestra propuesta. Las obras de arte son aquí fuentes de información al igual que los documentos escritos de variado tipo. La perspectiva que puede entonces adjudicarse a este trabajo es la institucional, la que consideramos como una manera distinta de hacer historia del arte que no parte de las obras sino de la institución museal y de cómo esta última muestra, habla y escribe sobre las primeras.

1 De aquí en adelante se utilizará la sigla señalada, MAC, para referirse al Museo de Arte Contemporáneo de Chile. 
El problema fundamental que aborda este trabajo se presenta cuando, al consultar la selección de obras y el contenido de algunos escritos de carácter administrativo, se pregunta cuál es el principio rector que guió la selección de pinturas y el propósito del museo al momento de su fundación. Si bien los propósitos son múltiples y los criterios de selección variados, ambos suponen también un acuerdo para que aquel -el princio rector- pudiese llevarse a cabo, y es este acuerdo el que se pretende establecer aquí como hipótesis demostrable. La pregunta central entonces es: ¿en torno a qué supuesto teórico gira el discurso museológico del MAC en el año de su fundación? Ello supone, evidentemente, múltiples premisas de investigación. En este museo, al igual que en otros, la concepción museológica ha estructurado una aproximación a los objetos y prácticas artísticas que está apoyada en supuestos teóricos concretos, los cuales han sido objeto de estudio por parte de la historia del arte y, en mayor medida, la sociología y los estudios museales (o museológicos). La primera suposición, entonces, es que existe un discurso museológico de (y desde) la institución, que es transmisor de ideas y valores. La segunda es que este discurso puede entreverse en las obras que el museo conserva, las actividades que produjo, los documentos oficiales relativos a la institución y, por supuesto (en tanto este trabajo aborda también la narrativa del arte chileno a partir del MAC), la bibliografía general y específica acerca del museo y la universidad de la cual depende.

Bajo el supuesto de que es necesario un análisis discursivo sobre el museo y la historia del arte como condiciones de posibilidad del discurso del arte contemporáneo (y no solo contemporáneo), la respuesta a este problema, a modo de hipótesis, es la siguiente: el supuesto teórico del discurso del MAC en su año de fundación -y, en parte, en el año anterior- es concebir, seleccionar y exponer el arte chileno (especialmente pintura) como un panorama representativo tanto de la actividad artística como de la nación misma. Esta idea se sostiene, además, en una creencia bastante arraigada sobre la apreciación del arte chileno, que puede constatarse al leer la bibliografía sobre el tema. Esta es la creencia en una evolución formal del arte chileno en paralelo a la formación de la nación, desde los orígenes de la República a principios del siglo XIX, hasta los años cuarenta del siglo xx (década de fundación del MAC), cuyo desarrollo (como expresión artística) se concibe como un espejo de la nación, principalmente en sus costumbres y paisajes.

Para la detección del problema y la construcción de la hipótesis se consultaron fuentes documentales escritas y visuales. Las principales son los boletines de la Universidad de Chile; periódicos chilenos y extranjeros que se refieren al MAC; discursos y actas de fundación de la institución; el catálogo de obras con que se dio inicio al museo; documentos epistolares referentes al museo, la universidad y las personas asociadas a la institución; la memoria oficial del Instituto de Artes Plásticas de la Universidad de Chile; decretos y artículos legales y administrativos acerca de la fundación y funcionamiento del museo y, por último, bibliografía general y particular sobre el MAC, la historiografía del arte chileno, la pintura chilena y los conceptos centrales de la 
museología y museografía con los que se han construido y analizado las instituciones museales de Chile y el extranjero.

\section{Créase el Museo de Arte Contemporáneo}

Las palabras del entonces rector de la Universidad de Chile, Juvenal Hernández, en el discurso inaugural del museo, en agosto de 1947, son bastante claras respecto a los planteamientos de esta investigación. Las tomaremos como el punto de partida para desarrollar los argumentos que sostienen nuestra hipótesis:

Estimular las artes y propender su desarrollo, es preocupación constante de la Universidad de Chile. La pintura, escultura y las artes decorativas han logrado en nuestro país un desarrollo que nos permite afirmar con absoluto convencimiento que ellas constituyen uno de los aspectos de nuestra cultura que ha proporcionado a la vida de la República, una nota permanente de elevado valor espiritual a pesar de los cortos años que nos separan de las primeras manifestaciones de esta índole, a mediados del siglo XIx, lo que constituye una verdadera infancia, si se considera el largo camino que necesitan recorrer las artes formales para alcanzar madurez de estilo y llegar a tener las características genuinas de la expresión de un pueblo.

En primer lugar, hay que insertar la creación y función del MAC dentro de la lógica de pertenencia a una universidad pública, en ese momento, la más grande del país. Tal como se propone en el texto Museo de Arte Contemporáneo 2005. Refundación, desde su fundación el museo es indisociable del Estado y la universidad (Museo de Arte Contemporáneo 15). El propósito de difusión del museo, perteneciente al Instituto de Extensión de la Facultad de Artes Plásticas, debe insertarse en la obligación legal y moral de la Universidad de Chile de dirigir y educar al país como una extensión visible, manifiesta y evidente del aparato estatal. En el mismo texto, se plantea que se crea el MAC con el objetivo de desarrollar, administrar y materializar las políticas de extensión (de la universidad) (21). En este sentido, es lógico que el museo albergue un conjunto de valores e ideas que transmitir mediante la exposición de obras y la elaboración de documentos; si no completamente una vocería del Estado, se trata al menos de un conjunto coherente de ideas sobre el universo representacional de las artes y el mundo a partir de la colección de obras que posee. "Las obras [en el museo] van a comunicarse entre ellas de una manera totalmente imprevisible e imaginaria. Es el principio de identidad -sin el cual no hay historia del arte ni historiografía general", escribió Jean-Louis Déotte (47) en Catástrofe y olvido (1998). Podríamos añadir que en este espacio se recogen y suspenden imágenes sin borrar su alcance narrativo (poesía, mito) o, mejor dicho, transformando su narratividad inicial y sus referencias para unirlas, resignificarlas y convertir todo su sentido particular en un gran relato común y nacional. 
En efecto, en el epílogo de La Construcción de lo Contemporáneo. La Institución Moderna del Arte en Chile (1910-1947), se refiere al proyecto cultural sobre el que se funda el Palacio de Bellas Artes en 1910. Los autores argumentan que es lícito pensar que la historia del arte en Chile, enmarcada en dicho proyecto cultural, no fue sino una herramienta política de una clase dirigente que intentaba confeccionar un Estado a su medida, y que el arte, en ese caso específico, jugaba un rol primordial en la construcción de una nación moderna desde el plano simbólico-visual (Berríos, Cancino y Santibáñez 222). Era el año del centenario de la fundación nacional. Las razones para pensar que algo similar pudo haber ocurrido con la fundación del MAC en 1947 son igualmente lícitas, aunque con algunas salvedades. Si bien la fundación de un museo no tiene (y no debiese porqué tener) solamente fundamentos estéticos -si es que no toda propuesta estética es a la vez, en algún sentido, política, y esto no tendría por qué disminuir el valor de la institución ni el de las obras que contiene-, el MAC es más una aspiración de los artistas que la motivación de un gobierno central, a diferencia del Palacio de Bellas Artes.

"El MAC era una vieja aspiración de los artistas chilenos. Desde la generación del 13 se soñaba con dar forma a un museo que representara la obra de los artistas vivos, que informara permanentemente de las inquietudes que preocupan a los pintores y escultores del presente e incluso de las juventudes en formación" (Museo de Arte Contemporáneo 16). Estas son las palabras del fundador del museo, el artista Marcos Bontá, en la inauguración del edificio. No obstante, esta situación no tendría por qué anular la difusión de valores e ideas sobre el arte, la cultura y el país que ha emprendido el MAC, ni la base de su discurso museológico. En este sentido, la homogeneidad que crea el museo en su interior y sobre la cual construye su narratividad hacia el exterior es la condición de posibilidad para la transmisión de uno o varios mensajes, a la vez que la misma puesta en evidencia de la viabilidad de estudiarlo, comprenderlo y analizarlo. Se trata de algo que incluso ciertos autores han llegado a señalar como una ideología (61-71); no entraremos en este debate, pero sí podemos considerarlo como un intento sistemático y coherente de imposición, eliminación, discriminación y acuerdo. Para Douglas Crimp, el museo está fundado sobre las disciplinas de la arqueología y la historia natural, ambas heredadas, como apunta Jordi Pardo, de la antigüedad clásica; en este contexto, la historia de la museología sería la de los diversos intentos por negar la heterogeneidad del museo, de reducirlo a una serie o a un sistema homogéneo (75-92). Y este sistema homogéneo no es otro que la colección que posee.

De esta forma, bajo el supuesto de que el discurso museológico queda plasmado en la exposición, las piezas de la colección debiesen dar luces sobre los principales conceptos y nociones en los cuales se basó el Museo de Arte Contemporáneo para instaurarse como una institución que da a conocer obras artísticas bajo una visión particular. ¿Se trató de la creencia en una evolución formal del arte a través de la historia? ¿Se trató de poner en evidencia, materialmente, los conceptos privativos a 
un lugar -nacional/local? ¿Se creyó en un universo representacional coherente que capaz de producir una comprensión determinada del arte y del mundo? En las citadas palabras del rector de la universidad, Juvenal Hernández, se encuentran las claves para interpretar este discurso: "vida de la República", "verdadera infancia", "madurez de estilo" y "expresión de un pueblo". Veremos que son los principios rectores de la narratividad del MAC, pues constituyen aquellos valores fundamentales que pretendía transmitir a través de su puesta en evidencia tanto material como simbólica. Si es difícil hablar de este museo como una obra de arte total, en que incluso el edificio es concebido como una obra de arte por sí misma, sí es posible hacer la analogía de esta institución como un faro y como un cruzado, alternándose temporalmente. Esto quiere decir que se debe concebir al museo como un centro simbólico que ilumina la nación, es decir, como un elemento activo que interviene en ella.

Ahora bien, a la pregunta de Déotte: “QQuién está habilitado para firmar, legitimar, testimoniar, en definitiva, para representar?” (69), la respuesta sería la nación, la gran comunidad, hija del siglo XIX, que se ve orientada en el gusto (estético) por estos grandes contenedores de símbolos llenos de referencias que, idealmente, los sujetos podían y debían juzgar para crear lugares y momentos de pertenencia a una tierra y a todo lo que ella contiene. Si seguimos esta línea, no es difícil comprender por qué entre finales del siglo xix y las primeras décadas xx en América Latina se produjo una relación tan estrecha entre el libro y el objeto, entre historiografía y museografía histórica, como propuso Pedro Alayza. Durante estos años su interdependencia fue total y, podríamos añadir, lo fue también la dependencia de los ciudadanos-observadores hacia estos dos aparatos. ¿Por qué? Porque el historiador siempre ha necesitado, para proclamarse como tal, de documentos y objetos que le permitan fabricar su historia, su gran relato. Por otro lado, el museógrafo necesita de esos mismos objetos y, además, del relato del historiador para dotar de narratividad y poder recrear un pasado que ya no está, una cultura que se perdió, pero que se presupone importante y dotada de un valor histórico. Y el ciudadano-observador, por otro lado, necesita de todo esto -de este relato con imágenes, como podríamos resumirlo- para dotar de sentido todo aquello que ahora ve suspendido (en tiempo y espacio), retomado y desanclado en el museo, descontextualizado de su situación original. Un saber dirigido, una ficción que debía ser real y una narración que necesitaba ser evidenciada, erudita, lógica y nacional.

Si los documentos de la memoria (el archivo) no se ponen a errar por sí mismos, como propuso Déotte (48), separándose de este gran teatro que es el museo (de memoria o de olvido), lo que se valida en este momento es la posibilidad de establecer uno o grandes relatos políticos, mitológicos incluso, mucho más que estéticos, sobre aquellos fragmentos (obras) que ahora vuelven a poseer identidad (aunque otra), sentido y, ante todo, semejanza. El museo asemeja, iguala, asimila y hereda aquello que perteneció a distintos contextos, lugares y tiempos; que antes de arte fueron ídolos, símbolos, dioses, héroes que jamás merecieron una contemplación estética desinteresada, y ahora pertenecen todos juntos, igualados, a un proyecto comunitario 
ideológicamente potente. Hubo que retomar aquello que fue dejado como si se nos hubiese legado - para tomar los términos de Déotte-, pasando del olvido desinteresado a una herencia intencionada, aunque artificial, para conservarla, restaurarla, mostrarla y, sobre todo, dirigirla.

\section{Panorama, conjunto, progreso, evolución}

Al final de su texto "Panorama de la Pintura chilena" - publicado en el Boletín informativo de la Universidad de Chile, correspondiente al mes de julio y agosto de 1946-, el pintor chileno Armando Lira afirma lo siguiente:

Las festividades conmemorativas del Centenario en 1910 ofrecieron un espectáculo de gran revuelo en la Historia de nuestra pintura: la exposición internacional. (...) Pero el hecho más trascendental de esta exposición, lo constituyó, sin duda, la demostración de pintura chilena. Allí se pudo valorar su efectivo progreso (...) Un examen del panorama evolutivo de la pintura chilena permite señalar el año 1920 como la fecha en que se inicia la renovación expresiva de las artes plásticas. El acontecimiento tuvo su origen en la formación del grupo de Montparnasse.

Un documento administrativo del año anterior a la fundación del museo contiene aquellos epítetos que el rector de la Universidad de Chile adjudicó a la pintura chilena el día de la inauguración del MAC: la creencia en una evolución de las artes en Chile bajo la lógica del progreso decimonónico y la consideración fundamental de la colección del MAC como un panorama de la pintura nacional que refleja al pueblo chileno. De esta forma, el arte aquí es tenido como un objeto de reflexión en ambos sentidos de la palabra, activo y pasivo. Activo en tanto es un objeto que invita a pensar en él, sobre él y con él, del arte, la cultura y el mundo. En su segunda acepción, como un reflejo del quehacer del pueblo y de la formación de la nación y sus instituciones. Al respecto, es lúcido el párrafo con el que Pedro Zamorano inicia su artículo "Fernando Álvarez de Sotomayor y la pintura chilena":

La pintura chilena comienza a hacer su historia con el nacimiento de la República, en 1810. Antes de esa fecha, la Colonia había impuesto un arte y un repertorio temático que se fundamentaba en motivos religiosos. Consolidada la Independencia, comienza en Chile un período de profundos cambios culturales que otorgan a la naciente pintura republicana nuevas y más amplias posibilidades de expresión (209-21).

Misma apreciación que hiciese Antonio Romera en Historia de la pintura chilena: "La vida de la pintura chilena es breve, tan breve como la historia del país" (11).

Parece ser que el concepto de "historia del arte" es el que se encuentra en juego cuando se escribe sobre arte, mucho más problemáticamente que el de "arte" por sí 
solo, al menos en este caso específico. Pues son los libros y los museos los soportes del canon de la historia del arte, ese canon basado en la eliminación, selección y homogeneidad de lo que es considerado arte y lo que no; en un museo, lo que no se muestra es tan decidor acerca de su orientación cultural y política como aquello que sí. Proceso que, como sabemos, se verbaliza hacia el exterior en forma de discurso, coherente y conciso acerca de valores e ideas específicas. El museo en general, y el MAC en específico, son modos de dar a ver, al igual que el libro. Y tal como propone Carmen García en El Mito de la Historia del Arte, el museo no es otra cosa que un espacio de normalización e imposición de un proceso de equivalencia, tanto formal como de contenido y, lo que es más importante, un lugar que ha dado la imagen a la historia y un punto de encuentro (visual) con ciertos momentos pasados (225-64). Ciertos momentos que parecen dominar la escritura sobre arte en Chile, al menos hasta el momento de creación del MAC en 1947, como son el nacimiento de la República en 1810 y el Centenario de la nación en 1910, ambos acontecimientos políticos. Sabemos, no obstante, que el arte no progresa y tampoco sigue un patrón evolutivo de carácter biológico, como si tuviese una forma predefinida de antemano, un desenvolvimiento que provocara que todas las formas que adquirieran no fueran sino etapas previas en el camino para alcanzar esa forma ya definida, aunque desconocida. David Pérez hizo una reflexión al respecto que resulta bastante aclaratoria: nada hay que progrese, escribe, salvo la voluntad institucional de perpetuar el fantasma del futuro o del progreso, ese fantasma que nos muestra que todo debe cambiar para seguir igual (299-308). Es decir, se trata de un constante gatopardismo.

Son numerosas las apariciones de adjetivos calificativos que suelen asignarse al arte chileno en los documentos, oficiales y no oficiales, respecto al MAC. En el diario El Mercurio del día 24 de septiembre de 1946 aparece un artículo con el título de "Famosa revista británica de arte dedica un número completo a Chile". Un extracto señala lo siguiente:

La recopilación de las fotografías de las obras mismas no fue tan difícil como la obtención de los datos completos a la vez que reunidos sobre la evolución de las artes en Chile y una apreciación sobre su estado actual, para ello confeccionaron cinco artículos originales de los cuales el señor Walker [el entonces Embajador de Chile en Gran Bretaña] está muy satisfecho porque su conjunto constituye un verdadero panorama de la Historia artística nacional. Uno de ellos titulado La evolución Histórica de las Bellas Artes en Chile, encomendado al profesor Eugenio Pereira Salas (desde 1541 a 1910) fue premiado.

Esta mención a un hecho extranjero que atañe al quehacer artístico nacional, y que menciona los mismos conceptos que se han señalado ya, no es una excepción. El periódico peruano La Crónica del día 16 de octubre de 1946 tituló una noticia: “Con gran éxito se inauguró ayer la exposición de pintura chilena”, que describió de esta manera la muestra de pintura nacional en ese país, en la voz del Doctor Luis Valcárcel, 
Ministro de Educación Pública: "Esta noche, por magia del arte, tenemos a Chile a la vista, sentimos la presencia de Chile como si de pronto estos cien óleos fueran otras tantas ventanas abiertas al panorama chileno: naturaleza y hombres, geografía y cultura" . Esta vez se hizo referencia explícita a la asociación establecida al principio de este trabajo: el doble significado de panorama. Por un lado, es el conjunto de lo más representativo de la pintura nacional, y por otro es una vista hacia el país, el reflejo de sus costumbres, gentes y, sobre todo, paisajes.

El diario El Mercurio del día 12 de noviembre de 1946 publicó una noticia titulada: "Exposición de pintura contemporánea brasileña se inaugura esta tarde", la que señaló: "Toman parte en esta exposición las firmas más destacadas y representativas de la pintura actual de Brasil (...) Esta exposición permitiría al público chileno observar el grado de progreso de las artes plásticas de la nación vecina". Una vez más, los mismos adjetivos se utilizan, ahora para catalogar una exposición de pintura extranjera, haciendo suponer que la escritura sobre las artes en esta época asumía como paradigmas las ideas que hemos descrito: la creencia en un progreso de las artes plásticas que configuran un panorama representativo tanto de la práctica como del pueblo al que pertenecen. El año de la fundación del MAC, dos periódicos nacionales titularon prácticamente del mismo modo una exposición inaugurada en distintas ciudades. $E l$ Sur, de Concepción, el día 11 de marzo de 1947 señala: "Análisis panorámico de la pintura en cien años hizo ayer el artista Marcos Bontá." Y La Discusión, de Chillán, el día 23 del mismo mes tituló: "El panorama del arte pictórico chileno nos hizo conocer la amena charla de Tomás Lago".

La importancia de estas referencias radica también en que señalan la colección de pinturas que el Instituto de Extensión de la Facultad de Artes Plásticas de la Universidad de Chile, antes de la fundación del museo, estaba iniciando y exhibiendo tanto en el extranjero como en las diferentes ciudades del centro y sur del país. Para la prensa y las personas encargadas de estas exposiciones, el elemento aglutinador de la incipiente colección que luego pasaría a formar parte de la colección permanente del MAC era justamente el hecho de que se tratase de un conjunto plenamente representativo de la pintura chilena y del país. Así, el Boletín informativo de la Universidad de Chile $\mathrm{N}^{\circ} 15$ del año 1946, se tituló Gira al sur de obras de la pintura seleccionadas del Salón Oficial de 1946, y señaló lo siguiente: "Muestra restringida de lo que representa actualmente el panorama de la pintura chilena, y aún, del Salón Oficial mismo, donde el escritor Tomás Lago habló en Chillán sobre el tema La Pintura Chilena”. A esto le sigue una lista de artistas chilenos que se tendrá presente para formar la Galería de Arte Contemporáneo Nacional, que precede a la formación del MAC. Eran 69 artistas en total, de los cuales 52 se dedicaban a la pintura, cifra que aumenta al momento de la inauguración del museo y en la que se sumaron artistas extranjeros.

La primera constatación que puede hacerse sobre el catálogo de obras que la Universidad de Chile exhibió ese año en su colección, junto con el conjunto de obras que fueron enviadas a la exposición de arte chileno en Colombia ese mismo año, el 
catálogo de obras en la inauguración del MAC y la lista de cuadros pertenecientes al exdepartamento de Bellas Artes que fue traspasada a la universidad en 1948, es la absoluta preponderancia de la pintura de paisaje, seguida por la de género costumbrista y el retrato, muy alejado del primer lugar. Si nos centramos en la última colección nombrada, dieciocho de las veinte obras traspasadas a la universidad correspondían a paisajes del centro y sur del país, justamente el lugar donde radican tradicionalmente las características distintivas del folklore nacional y aquello que se ha denominado "chilenidad"; las dos obras restantes también retratan al pueblo chileno desde el género costumbrista: Mujer de pescados y Mujer de cacharros, ambas del pintor Roberto Márquez.

Una carta de Marcos Bontá al director de la Escuela de Artes Plásticas de la universidad, del 4 de agosto de 1947, indica lo siguiente: "Se ha propuesto preparar una colección de dispositivos en color, lo más completa que sea posible de las obras más representativas de la pintura chilena, con el fin de disponer de un conjunto que represente la historia de nuestra pintura, que pueda servir para los propósitos de difusión que persigue este organismo". Bontá adjunta una lista con las obras de las que se posee una diapositiva a color. Además de volver sobre los tópicos usuales ya descritos anteriormente -esos lugares comunes al momento de hablar y escribir sobre arte chileno hasta la década del cuarenta-, la presencia de la pintura de paisaje sigue siendo la principal: trece pertenecen a este género y seis se reparten entre pintura costumbrista y retratos.

\section{Conclusiones. EI MAC como construcción discursiva}

Elaborar un concepto de panorama desde una perspectiva genealógica supone ordenar sus distintos significados en los momentos en que se escribe de y con este concepto. En primer lugar, se trata de un concepto moderno, de espectáculo, con acento en la exhibición y perteneciente al siglo XIX, mismo siglo donde se consolida la pintura de paisaje de raíz holandesa pero adoptada por la pintura inglesa, nacionalidad de uno de los precursores del arte chileno, según el consenso historiográfico: Charles Wood. Este concepto además sugiere las ideas de enciclopedia y de totalidad, pero también de resumen y síntesis, apertura y cierre de campos. En este sentido, el panorama como lugar común supone un acuerdo y, como tal, una selección y clasificación de lo que entra dentro de ese ámbito y lo que queda fuera. Se trata, en definitiva, del establecimiento de un canon de pintura y, por extensión, de un discurso de la historia del arte inaugurada por el museo en tanto otorga una síntesis cabal del ir y venir del arte en Chile, estableciendo un origen (el cual, sin embargo, es siempre retrospectivo) en la fundación de la nación y un proceso de evolución formal que desemboca naturalmente en una madurez de estilo, hacia el Centenario de la República.

En su "Panorama de la Pintura chilena", Armando Lira sostiene que las influencias indígenas en la pintura chilena son nulas, a diferencia de países como Perú, Bolivia, 
Ecuador y México, y que el desarrollo de esta comenzó con José Gil de Castro (17851841), aunque los precursores de la pintura chilena son, a juicio del autor, el inglés Charles Wood, el alemán Mauricio Rugendas y el francés Raimundo Monvoisin. No sabemos si esto se debe a un profundo racismo (considerando que Gil de Castro era peruano) o a que aún no estaba formada la nación con sus características distintivas. Como sea, es notorio que los considerados precursores de la pintura nacional fueran un paisajista, un pintor costumbrista y otro academicista. Zamorano también consideró a estos artistas dentro de los precursores de la pintura nacional (209), lo mismo que Romera. Este lugar común, sin duda, tiene otra lectura cuando Romera establece cuatro constantes en la pintura chilena que, a su juicio, reaparecen siempre: paisaje, color, influjo francés y carácter (12-5). Es decir, paisajismo, costumbrismo y academicismo serían la característica principal, el rasgo concreto y el perfil peculiar del arte nacional. De hecho, más adelante, el mismo autor afirmó: "Enseguida aparecen en los artistas que siguen el amor por el paisaje. Incluso en los precursores que llegan a Chile formados y con un concepto estético personal, se da ese vuelco hacia el mundo exterior" (Romera 13).

De esta forma, el discurso museológico del Museo de Arte Contemporáneo de la Universidad de Chile descansa en nociones comunes de la historiografía del arte chileno, al menos aquellas escritas hasta el momento de inauguración de la institución, el marco temporal de este trabajo. Concebir la producción pictórica nacional como un panorama de lo más representativo del arte chileno y de Chile mismo está en directa relación con el contenido de las pinturas exhibidas en el MAC en este momento, en que el paisajismo es el género privilegiado, seguido por la pintura costumbrista. Ello, sin perjuicio del otro propósito del museo y el más general como institución, dependiente de la principal universidad del Estado.

"Impulsados por la voz de la conciencia, por la admiración que profesamos al suelo que nos vio nacer, los artistas genuinos queremos incorporarnos al esfuerzo común para contribuir, con nuestro específico aporte, a hacer de nuestro territorio un hogar no más grande en extensión, pero sí digno para los chilenos" (Museo de Arte Contemporáneo 2). Estas son las palabras iniciales de Bontá quien, como director del Instituto de Extensión de Artes Plásticas de la Universidad de Chile, fundó el Museo de Arte Contemporáneo en 1947. La indisociabilidad del museo de la universidad y de esta con el Estado es absoluta: la misión de la universidad, encomendada por el Estado, era organizar culturalmente la nación; también el museo debe entenderse en esa lógica, con un propósito educativo, propagandístico, nacional y, sobre todo, panorámico. ¿Qué debía exhibir el recién inaugurado museo, según estos propósitos? Los criterios con los que se eligió la colección el año de la fundación pareciesen radicar no en un apego al pasado, como el nombre mismo del museo así lo indica, sino que en una aferrada aprehensión de la producción presente, contemporánea a la misma formación de la institución y paralela a la de la República.

¿Se intentó, en la primera mitad del siglo xx, presentar la pintura del siglo XIX como aquel momento en que el arte habría alcanzado un estatuto moderno? ¿Se en- 
tiende, entonces, el arte chileno del siglo $\mathrm{xx}$-ese que busca exhibirse permanentemente en el museo- como la consecuencia natural e inevitable del desarrollo anterior de la pintura chilena? Si recordamos las palabras del rector de la universidad en el catálogo inaugural de la exposición en 1947, la respuesta pareciera ser afirmativa:

A pesar de los cortos años que nos separan de las primeras manifestaciones de esta índole, a mediados del siglo xıx, lo que constituye una verdadera infancia, si se considera el largo camino que necesitan recorrer las artes formales para alcanzar madurez de estilo y llegar a tener las características genuinas de la expresión de un pueblo (Hernández).

De esta forma, al panorama general de lo más representativo de la pintura chilena, los pilares fundamentales del arte nacional y el objetivo educativo nacional que asume la universidad, sumamos ahora la creencia en una evolución formal del arte a través del tiempo. Conceptos como "infancia" (para referirse a la pintura del siglo XIX), y "madurez de estilo" (para referirse a la de principios de siglo $\mathrm{xx}$ ) serán referencias usuales del propósito primero del MAC, referencias que parecen configurar a esta institución como una construcción discursiva sobre el arte del pasado y del presente en tanto punto cúlmine de un universo representacional coherente que creyó producir una determinada comprensión del arte y la cultura chilena hasta ese momento.

\section{Referencias}

Anónimo. “Análisis panorámico de la pintura en cien años hizo ayer el artista Marcos Bontá”. El Sur, 11 de marzo de 1947. Impreso.

Anónimo. “Con gran éxito se inauguró ayer la exposición de pintura chilena”. La Crónica, 16 de octubre de 1946. Impreso.

Anónimo. "El panorama del arte pictórico chileno nos hizo conocer la amena charla de Tomás Lago". La Discusión, de Chillán, 23 de marzo de 1947. Impreso

Anónimo. "Exposición de pintura contemporánea brasileña se inaugura esta tarde". El Mercurio, 12 de noviembre de 1946. Impreso.

Anónimo. "Famosa revista británica de arte dedica un número completo a Chile". El Mercurio, 24 de septiembre de 1946. Impreso.

Anónimo. "Gira al sur de obras de la pintura seleccionadas del Salón Oficial de 1946”. Boletín Informativo, Universidad de Chile, julio-diciembre 1946. Impreso.

Alayza, Pedro Pablo. "El contenido de los museos entre el incremento y la cultura del espectáculo”. Aprendiendo de Latinoamérica. El museo como protagonista. Ed. María Bellido. Gijón: Trea, 2007. 15-33. Impreso.

Berríos, Pablo, Eva Cancino y Kaliuska Santibáñez. La construcción de lo contemporáneo. La institución moderna del arte en Chile (1910-1947). Santiago: Departamento de Teoría e Historia del Arte, Universidad de Chile. 2012. Impreso. 
Bontá, Marco. "Para Director de la Escuela de Artes Plásticas de la Universidad de Chile". 4 de agosto de 1947. (Comunicación personal). Impreso.

Crimp, Douglas. "En las ruinas del museo". La Posmodernidad. Ed. Hal Foster. Barcelona: Indice, 2008. 75-92. Impreso.

Déotte, Jean-Louis. Catástrofe y olvido: las ruinas, Europa, el museo. Santiago: Cuarto Propio. 1998. Impreso.

García, Carmen. “El Mito de la Historia del Arte”. Ars Longa 14-15 (2005-2006): 225-264. Impreso.

Hernández, Juvenal. "Discurso Inaugural”. Catálogo Inauguración Museo de Arte Contemporáneo de la Universidad de Chile. Agosto 1947. Santiago de Chile. Impreso.

Lira, Armando. "Panorama de la Pintura chilena". Boletín Informativo, Universidad de Chile, julio-agosto 1946. Impreso.

Museo de Arte Contemporáneo. Museo de Arte Contemporáneo 2005. Refundación. Santiago: Facultad de Artes, Universidad de Chile, 2006. Impreso.

Pardo, Jordi, "Ideas e Ideología en el proyecto museológico". Museo 5 (2000): 61-71. Impreso.

Pérez, David, "La anarsticidad domesticada (o de cómo la institución arte construye objetos, actitudes y conceptos)”. Ars Longa 7-8 (1996-1997): 299-305. Impreso.

Romera, Antonio. Historia de la pintura chilena. Santiago: Zig-Zag, 1968. Impreso.

Zamorano, Pedro. "Fernando Álvarez de Sotomayor y la pintura chilena". Anales de Historia del Arte 2 (1990): 209-221. Impreso.

Recibido: 23 mayo 2014 Aceptado: 07 septiembre 2015 